\title{
In Vitro and In Vivo Pharmacological Efficacy of New Drugs
}

\section{Bhargava $\mathrm{K}^{*}$}

UI Centre (Drug Discovery@UIC), College of Pharmacy, University of Illinois at Chicago, Chicago, IL-60612, USA, Tel: 312-206-1162; E-mail: karumudi@uic.edu

Journal of Pharmacognosy\& Natural Products aim to provide high quality research on innovative medicinal products obtained from plants. Researchers from across USA, India and Croatia have contributed their research outcomes as articles to this current Issue 2, Volume 2, which included 3 editorials and a research article.

Heidari A., in an editorial discussed about the new headspace solvent micro extraction (hsme) method used in the extracting anticancer compounds, such as n-tolyl-sulfonyl-phosphoramid-saeuredichlorid from plant samples into micro drop. The Present study employed advanced technologies like Reflectance Fourier Transform Infrared Spectroscopy (ATRFTIR), FT-Raman, Mass, HNMR, CNMR and PNMR spectroscopies [1].

Coatian author Maleš Ž, et al., in the editorial article envisaged the $21^{\text {st }}$ century's issue over the counter (OTC) availability of antioxidants (polyphenols) as a prophylactic dietary supplements. Polyphenols offers several potential benefits to human. The author paid further attention on the doses and concentrations achieved in blood, as flavonoids can have proaggregatory effect on blood, depending upon the concentration. The article remarked that the vitro studies cannot be easily extrapolated as in vivo observations, as the in vitro data tends to overestimate the pharmacological effect [2].
Researcher Tiwari SS., in an editorial article discussed about the importance of medicinal plants- and its applications. The Author sighted a number of plant based drugs, such as vincristine, taxol, digoxin, quinine, reserpine, opioids, ephedrine, colchicine, rutin, coumarins, anthraquinones, etc. that do not have any synthetic substitute, which are still used as for therapy. The author recommended to explore their wide areas of applications further in studies [3].

Vohra K, et al., investigated about the adverse effects in the management of hyperlipidemia using statins, fibrates, bile acid,sequestrants and niacin. The clinical trial outcome suggests that the extracts of Lens culinaris contain active phytoconstituents, which might be responsible for anti-hyperlipidemic activity of the seeds [4].

\section{References}

1. Heidari A (2016) Extraction and Preconcentration of N-Tolyl-SulfonylPhosphoramid-Saeure-Dichlorid as an Anti-Cancer Drug from Plants: A Pharmacognosy Study. J Pharmacogn Nat Prod 2:e103.

2. Maleš Ž, Bojic M (2016) Antioxidant Potential of Polyphenols: In Need for Critical Assessment of In Vitro Results. J Pharmacogn Nat Prod 2:e104.

3. Tiwari SS (2016) Medicinal Plants-Perspectives and Needs. J Pharmacogn Nat Prod 2:e105.

4. Vohra K, Gupta VK, Dureja H, Garg V (2016) Antihyperlipidemic Activity of Lens culinarisMedikus Seeds in Triton WR-1339 Induced Hyperlipidemic Rats. J Pharmacogn Nat Prod 2:117. *Corresponding author: Bhargava K, UI Centre (Drug Discovery@UIC), College of
Pharmacy, University of Illinois at Chicago, Chicago, IL-60612, USA, Tel: 312-206-1162; E-mail: karumudi@uic.edu

Received January 12, 2016; Accepted January 24, 2016; Published January 27, 2017

Citation: Bhargava K (2017) In Vitro and In Vivo Pharmacological Efficacy of New Drugs. J Pharmacogn Nat Prod 2: e106. doi: 10.4172/2472-0992.1000e106

Copyright: (c) 2017 Bhargava K, et al. This is an open-access article distributed under the terms of the Creative Commons Attribution License, which permits unrestricted use, distribution, and reproduction in any medium, provided the original author and source are credited. 